\title{
Regenerating leather waste for flexible pressure sensing applications
}

\author{
Jie Lei ${ }^{\dagger}$, Binghua Zou ${ }^{\dagger}$, Runan Zhang, Kang Zhang, Ruijie Xie, Weina Zhang, Jiansheng Wu, Sheng Li ${ }^{*} \mathbb{D}$, \\ Bing Zheng ${ }^{*}$ and Fengwei Huo*
}

\begin{abstract}
Pressure sensor can be applied in a wide range of fields, such as voice recognition, human motions detection and artificial electronic skin, the sensing of which is greatly influenced by the flexibility and stretchability of substrate materials. Here, based on the piezoresistive effect, new kinds of flexible pressure sensors have been realized from a pair of flexible and biocompatible collagen films: one is coated by silver nanowires (Ag NWs) and the other by interdigital electrode, respectively. The collagen films are regenerated from leather waste and could bring economic benefits to society. The prepared pressure sensors are applied for voice recognition and human motion detection.
\end{abstract}

Keywords: Leather waste, Collagen films, Pressure sensor, Flexible, Human motion detection

\section{Introduction}

Driven by the development of intelligent manufacturing, intelligent robotics, human-machine interaction and biomedical diagnosis have received extensive attention [1-8], and they have high requirments for flexible bending performances. However, many traditional electronic devices are based on rigid semiconductor silicon materials. Thus the bending and elongation characteristics of the devices are significantly limited. The development of flexible sensing techonology could solve this problem effectively, such as new types of flexible pressure sensors, which have shown part of characteristics of human skin [4-10]. Moreover, a flexible sensor with the property of external forces perception can be used for bionic electronic skin and various wearable electronic devices $[9,10]$.

There are some key components which determine the basic performances of the electronics, such as active materilas, substrate materials and electrodes. Among these considerations, the substrate materials play an important role [5, 7-12]. The substrate materials with ideal flexibility and robust mechanical strength can provide a sensitive response to the external pressure. Generally, industrial fabricated polymers and some natural

\footnotetext{
*Correspondence: iamsli@njtech.edu.cn; iambzheng@njtech.edu.cn; iamfwhuo@njtech.edu.cn

Jie Lei and Binghua Zou are equally contributed to this work. Key Laboratory of Flexible Electronics (KLOFE) \& Institute of Advanced Materials (IAM), Nanjing Tech University (NanjingTech), 30 South Puzhu Road, Nanjing 211816, People's Republic of China
}

macromolecular materials can both serve as flexible substrates [10-27]. Comparing the two kinds of materials, the latter one has prominent advantages due to the biocompatibility, biodegradability and sustainability, thus serving as desirable substrate for the next-generation flexible electronic devices [13].

Normally, many types industrial fabricated polymers, such as polydimethylsiloxane (PDMS) [10, 14, 15], poly (ethylene terephthalate) (PET) [16, 17], poly (ethylene naphthalate) (PEN) [11] and poly (imide) (PI) $[15,18]$ have been used as substrates for flexible electronic devices. Bao's group fabricated a flexible and sensitive organic thin film transistor based on PDMS, which can be used for pulse monitoring in cardiovascular surveillance [10]. Though these polymers have prominent advantages in flexibility, stretchability and even excellent fit between the device and tissue, their manufacturing process and fabricated devices are not eco-friendly in the long term. However, natural macromolecular materials, such as collagen [19], silk fibroin [20-22], cellulose [23-26], chitin [27] and so on, will overcome those difficulties and be the ideal choices in the development of electronic devices due to their flexibility, biodegradability and biocompatibility. Roger's group integrated thin-film silicon with transient circuits based on silk films [20]. Their device can be used for versatile applications due to the tunable degradation time of silk-fibroin films. However, 
the fabrication of their devices are still in high-cost and undesireable.

Considering that approximately $200 \mathrm{~kg}$ of leather would be manufactured from 1 ton of wet-salted skin/ hide, resulting in the generation of more than $600 \mathrm{~kg}$ leather waste [28]. Collagen is an important component in leather waste. The usage of the above collagen can not only reduce the leather waste for the environment, but also promote the development of functional materials. In recent years, there have been many researches on the applications of collagen fibers from leather, such as using the collagen fibers to fabricate microwave absorption materials, anode materials, conductive leather and magnetic composites [29-32]. However, research on using collagen films as substrates from leather waste for flexible electronics has not been reported.

Herein, we present the use of regenerated collagen films from leather waste as the substrate to fabricate a flexible and transparent pressure sensor, which is piezoresistive-type. It consists of two collagen films coating with Ag NWs as active layers and painted with Ag paste as the interdigital electrodes, respectively (Scheme 1 ). The sensor is capable of converting mechanical pressure into electrical signal effectively, and the pressure could be driven by different motion ranges of human body, such as voice recognition, finger and wrist bending-releasing motions. These properties and characteritics rely heavily on the flexible collagen film. Due to the collagen film is biocompatible and comfortable to human skin, there are only small mechanical property mismatches between the prepared device and human body, making it quite promising to the applications for electronic skins.

\section{Main text}

\subsection{Preparation and Properities of the flexible collagen} film

The film is prepared by dissolving leather waste in ionic liquids (ILs). The pickled skin in this experiment is the source of collagen fibers, consisting of multiple collagen fibrils with a diameter of $100-500 \mathrm{~nm}$ (Additional file 1: Figure S1). The collagen fibrils are made up by several microfibrils which comprise tropocollagen molecule clusters with a diameter of about $1.5 \mathrm{~nm}$ and a length of $\approx 300 \mathrm{~nm}$ [33]. The hierarchical structures consisting of triple helical structure endow the collagen with robust strength and high stability. ILs have been widely used for dissolution and regeneration of biomaterials, such as cellulose and protein, and the experimental process has also been widely explored [34-38]. In addition, ILs have been considered as desirable green solvents to dissolve collagen fibers due to the excellent properties such as negligible vapor pressures, miscibility with water and organic solvents, and recyclability [39-41]. Here, the flexible collagen films can be obtained by the dissolution of collagen fibers in IL ([BMIM] Cl, 1-butyl-3-methylimidazolium chloride) and regenerated in precipitant (DI water) (Additional file 1: Figure S2). The dissolution mechanism of the collagen fibers in [BMIM] $\mathrm{Cl}$ can be found in Fig. 1a. According to the electron donor-electron acceptor (EDA) theory, the $[\mathrm{BMIM}] \mathrm{Cl}$ is dissociated at high temperature and the free $\mathrm{Cl}^{-}$acting as electron donor would associate with the hydrogen in the amino group, and the free $[\mathrm{BMIM}]^{+}$acting as electron acceptor would complex with the oxygen in the carboxyl group, the process of which would disrupt hydrogen bond between the collagen macromolecule chains and lead to the dissolution of the whole collagen [33]. In addition, [BMIM] $\mathrm{Cl}$ can be completely miscible with the deionized water while collagen cannot, so during the regeneration process, the hydrogen bond can be rebuilt between collagen chains as the [BMIM] $\mathrm{Cl}$ has been washed away. However, the quantity and position of some hydrogen bond differ from that of the original collagen due to the changing position of the collagen chains during the regeneration process, resulting in the change of structure and properties of regenerated collagen films.

The collagen fibers and regenerated collagen films are firstly studied by using Fourier-transform infrared (FT-IR) analysis (Fig. 1b). The peak of Amide A $\left(3308 \mathrm{~cm}^{-1}\right)$ represents $\mathrm{N}-\mathrm{H}$ stretching vibration absorption, which relates to the hydrogen bonds between the collagen chains. Amide I $\left(1659 \mathrm{~cm}^{-1}\right)$, Amide II $\left(1550 \mathrm{~cm}^{-1}\right)$ and the Amide III $\left(1450 \mathrm{~cm}^{-1}, 1241 \mathrm{~cm}^{-1}\right)$ represent $\mathrm{C}=\mathrm{O}$



Scheme 1 Schematic showing the source of collagen film and its application as the substrate for pressure sensors 


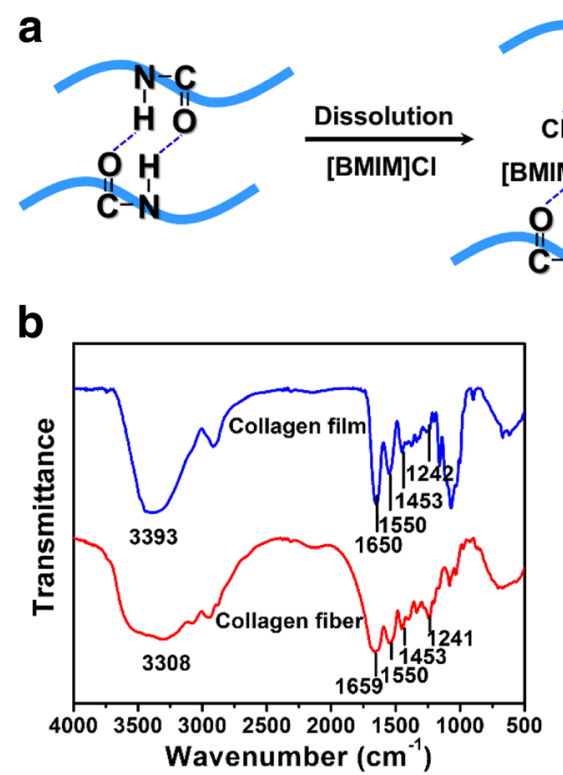

Fig. 1 Properties of collagen fibers. a Dissolution and regeneration mechanism of collagen fibers. b FT-IR spectra of collagen fibers and collagen films. c TGA profiles of collagen fibers and collagen films $\left(10^{\circ} \mathrm{C} \mathrm{min}{ }^{-1}\right.$ ramp, $\mathrm{N}_{2}$ atmosphere)

stretching vibration adsorbtion, $\mathrm{N}-\mathrm{H}$ bending vibration adsorbtion, C-N stretching vibration absorption and $\mathrm{N}-\mathrm{H}$ bending vibration adsorbtion, respectively $[42,43]$. The profile of the collagen film is similar to the collagen fibers, and this means they have similar chemical functions (Fig. 1b). However, there are also some differences which are clearly identified from the spectra. The peak of Amide A $\left(3393 \mathrm{~cm}^{-1}\right)$ in collagen film shifts to lower frequency and narrows down, indicating some hydrogen bonds have ruptured between the collagen chains, which is also consistent with the EDA theory. The collagen fibers possess an intensive band at $1659 \mathrm{~cm}^{-1}$ corresponding to Amide I in helical form. However, the peak of Amide I $\left(1650 \mathrm{~cm}^{-1}\right)$ in collagen film shifts to higher frequency, indicating that there are some changes with the triple helical structure of the collagen film.

To investigate the thermal stability of the collagen fibers and regenerated collagen film, we obtained the Thermo Gravimetric Analyzer (TGA) profiles of the collagen fibers and film $\left(10^{\circ} \mathrm{C} \mathrm{min}^{-1}\right.$ ramp, $\mathrm{N}_{2}$ atmosphere). Normally, The thermal stability of a large molecule depends on its molecular weight, spatial structure and intermolecular forces. Here, there are two main stages of the weight loss of the collagen fibers and films: one is at $40 \sim 150^{\circ} \mathrm{C}$, representing the loss of absorbed and bound water of collagen fibers and films; the other is at $200 \sim 500^{\circ} \mathrm{C}$, representing the thermal decomposition of polypeptide chains in collagen [44]. The decomposition temperature of the films $\left(254^{\circ} \mathrm{C}\right)$ is lower than that of the fibers $\left(276^{\circ} \mathrm{C}\right.$ ) (as shown in Fig. 1c). That is because the ILs dissolves collagen fibers mainly by breaking the forces of the hydrogen bonds and ionic bonds between the collagen molecules, and in the regeneration process, the location and quantity of the hydrogen bonds have changed and even some hydrogen bonds have been disrupted due to the high dissolution temperature.

The surface appearance, transparency and crystal structure of collagen films are analyzed by scanning electron microscope (SEM), Ultraviolet-visible (UV-vis) spectra and X-ray diffraction (XRD). The top and crosssectional-view SEM images of the collagen films reveal that the collagen films are compact (Fig. 2a, b). Figure 2c shows a magnified view of the cross-sectional image of the film, indicating the fabricated film is dense. The thickness of the collagen films can be controlled by changing the initial amount of the mixture solution distributed on the glass sheet. And the transparency of the collagen film is higher than $55 \%$ in the visible spectrum $(400-700 \mathrm{~nm})$ by the UV-vis transmittance spectra (Fig. 2d), which is an attractive advantage for electronic skin, such as artificial cornea $[45,46]$. The crystallization of the collagen films is investigated by XRD analysis (Fig. 2e). Three main diffraction peaks can be observed, and the diffraction peaks in $2 \theta=7.8^{\circ}$ produced in crystalline regions represent the distance between the molecular chains in collagen fibers [32]. Compared with that of collagen fibers, the diffraction peak of collagen film shifts to the left side, indicating the space between collagen molecular chains becomes lager and the chains are dispersed. It is notable that there exists a wide diffraction peak in $21.8^{\circ}$ generated in amorphous regions in the profile of the collagen fibers, indicating a diffuse scattering due to the multilayer 


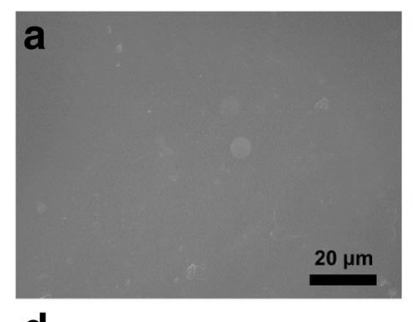

d

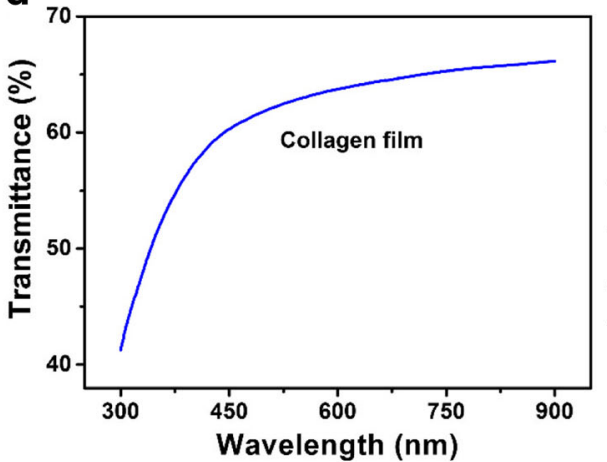

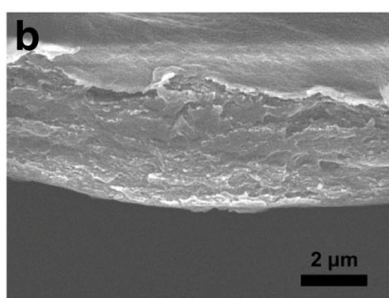



e

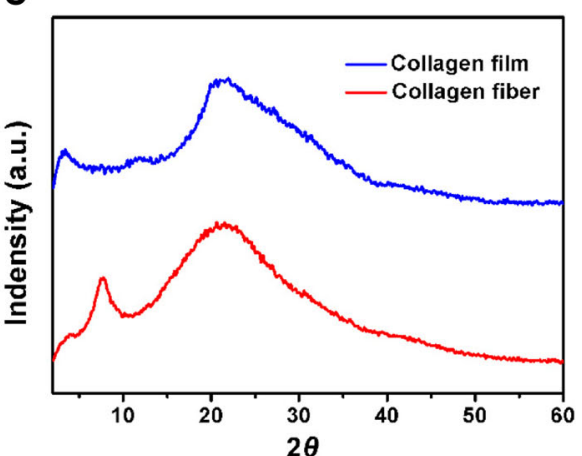

Fig. 2 Properties of the collagen film. a top-view and $\mathbf{b}$ cross-sectional view of the collagen film. c A magnified view of (b). $\mathbf{d}$ UV-vis transmittance spectra of collagen film. e XRD patterns of collagen fiber and collagen film

structure in the collagen fibers. However, for the collagen film, the peak in $21.8^{\circ}$ narrows down and the crystallinity increases.

\subsection{Preparation and performances of the flexible pressure} sensor

A flexible pressure sensor has been fabricated based on the regenerated collagen film, demonstrating the possibility of the film as substrate for the pressure sensing applications (Fig. 3a, b). In this work, the flexible pressure sensor is fabricated by two layers of collagen films coated with $\mathrm{Ag}$ NWs as the active layer and painted with $\mathrm{Ag}$ paste as the interdigital electrodes, respectively (Fig. 3c). Ag NWs have a concentration of $5 \mathrm{mg} \mathrm{mL}^{-1}$ and width of about $100 \mathrm{~nm}$ (Additional file 1: Figure S3). The Ag NWs are coated on the collagen films using a spin-coater at a rate of $2000 \mathrm{rpm}$, which results in a conductive film with a mean sheet resistance of $37 \Omega \mathrm{sq}^{-}{ }^{-1}$. The sensing principle of this pressure sensor is transducing the resistance change resulted from applied pressure into an electrical signal. When an applied pressure is put on the sensor, the amount of Ag NWs between interdigital electrode arrays was changed, leading to the change of electrical signal. Higher pressure would cause more Ag



b



C

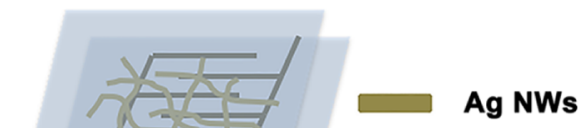

Interdigital electrode



Fig. 3 Fabrication and working principle of the device. a Large-scale uniform and transparent collagen films (scale bar $=1.5 \mathrm{~cm}$ ). $\mathbf{b}$ Photograph of the flexible and transparent pressure sensor (scale bar $=1.0 \mathrm{~cm}$ ). $\mathbf{c}$ Fabrication of a flexible pressure senor based on collagen films. $\mathbf{d}$ The illustration of the work principle of the pressure sensor 
NWs contacting with the electrodes, leading to more conductive ways (Fig. 3d).

Based on the above working principle of the sensor, the sensitivity, transient response analysis and stability performances of the device are investigated. Typical current-voltage $(I-V)$ curves of the sensor responding to different applied pressures are displayed in Fig. 4a. The resistance drops immediately along with the increasing pressure. As the applied pressure increasing, the amount of Ag NWs between interdigital electrode arrays increased, thereby enhancing electron transport and reducing the overall resistance of the sensor. The pressure signals can be read out when the operating voltage is $0.5 \mathrm{~V}$, which is favorable for portable diagnosis. And the applied pressures on the sensor are achieved by the equation: $\mathrm{P}=\mathrm{mg} / \mathrm{A}$, where $\mathrm{P}$ is the pressure, $\mathrm{m}$ is the mass of a counterweight, $\mathrm{g}$ is the gravity unit, $\mathrm{A}$ is the actual contact area between the counterweight and the effective part of the sensor. Here, a $1.1 \times 1.4 \mathrm{~cm}^{2}$ sheet glass is put on the device to apply a uniform pressure, so A is $1.1 \times 1.4 \mathrm{~cm}^{2}$ in fact. When pressure is gradually applied to the device, the sensitivity $\mathrm{S}$ can be defined as $\mathrm{S}=\left(\Delta \mathrm{I} / \mathrm{I}_{0}\right) / \Delta \mathrm{P}$, where $\Delta \mathrm{I}$ is the relative change in the current, $\mathrm{I}_{0}$ is the initial current when a $1.1 \times 1.4 \mathrm{~cm}^{2}$ glass is put on the device, and $\Delta \mathrm{P}$ is the change in applied pressure. To demonstrate the sensor's sensitivity to the quick change of different applied pressures, we obtained the real-time current changes of the sensor upon the pressure values from $64 \mathrm{~Pa}$ to $6364 \mathrm{~Pa}$. The current change responding to different applied pressure exhibits detecting and sensing capability of the sensor, and the sensitivity value in a range of $64 \mathrm{~Pa}-1909 \mathrm{~Pa}$ of our sensor is $13.33 \mathrm{KPa}^{-1}$ and $1.27 \mathrm{KPa}^{-1}$ in a range of $2545 \mathrm{~Pa}-6364 \mathrm{~Pa}$ (Fig. 4b). As the collagen film is swelling in DI water, the surface of the film is uneven during drying processes, which causes the first stage of the sensitivity diagram is high. When higher pressure is applied to the sensor, the sensitivity is reduced because the most important influence factor in this stage is the conductive ways resulted from the contact between Ag NWs and the electrode. Figure 4c shows the instant response of the sensor exhibits a response time of $349 \mathrm{~ms}$ and relaxation time of $147 \mathrm{~ms}$ under $636 \mathrm{~Pa}$, indicating the current changes rapidly respongding to the applied pressure, which can be expected to monitor human motions synchronously. To investigate the stability of the sensor, current changes versus time are obtained for the repeated loading/unloading under $3182 \mathrm{~Pa}$ for 900 cycles (Fig. 4d). The magnified view in the bottom of Fig. $4 \mathrm{~d}$ shows the middle and last 12
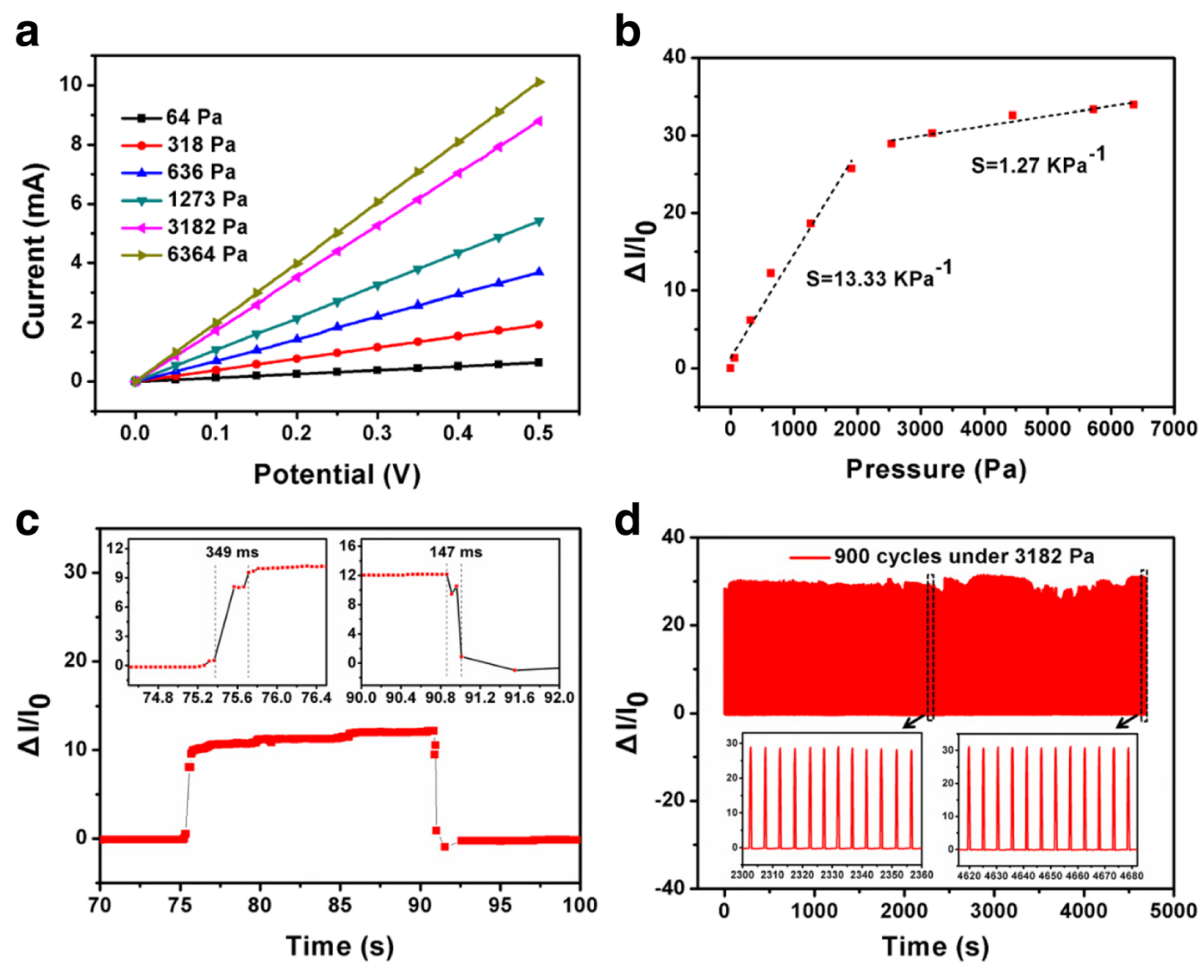

Fig. 4 Pressure sensing performances of the device. a Typical current-voltage curves of the sensor responding to different applied pressure. b Current changes of the sensor response to various applied pressure showing the pressure sensitivity value in a range of 64-1909 Pa is $13.33 \mathrm{KPa}^{-1}$ and $1.27 \mathrm{KPa}^{-1}$ in a range of 2545-6364 Pa. c Instant response of the sensor towards applied pressure showing a response time of $349 \mathrm{~ms}$ and relaxation time of $147 \mathrm{~ms}$ under $636 \mathrm{~Pa}$. $\mathbf{d}$ Working stability of the sensor for $900 \mathrm{cycles}$ under a pressure of $3182 \mathrm{~Pa}$ and the magnified view of the middle and last 12 cycles 
cycles, which shows the stable current changes responding to applied pressure, indicating the sensor has high stability, repeatability and durability.

\subsection{Human physical motions sensing}

The flexible pressure sensor is used to monitor different ranges of human motions, such as finger and wrist bending-releasing motions. First, we have investigated the electrical current values of the sensor recorded upon different applied pressures (Fig. 5a), which demonstrates the electrical signals generated upon applied pressure are sharp and reversible, indicating the steady and synchronous measurement of the human motions. Furthermore, the real-time current changes of the sensor are obtained upon different pressures. Responding to the increasing applied pressure, the current increases apparently whereas the resistance decreases, which demonstrates the reliability of the sensor for real-time monitoring (Additional file 1: Figure S4). In order to verify this, we investigate the monitoring performances of the sensor. The sensor is attached to the joint of an index finger of the volunteer with adhesive tapes (Fig. 5b). And the volunteer is conducted to perform finger bending-releasing motions. In detail, the current increased sharply responding to the bending motions and when the volunteer was conducted to perform the releasing motions, the current decreased due to the releasing deformation of the sensor. Notably, the current responses corresponding to bending and releasing motions exhibit stability and reproducibility, indicating the excellent reliability of the sensor. Furthermore, when the sensor is attached to the wrist of the volunteer to detect some large range of motions, apparent and repeatable current signals can also be recorded during the wrist bending-releasing motions (Fig. 5c). The current increased when the volunteer performed bending motions of the wrist, and then it decreased rapidly responding to the releasing motions due to the recovery of the sensor. These results demonstrate the capabilities of the sensor in detecting human motions, which might be beneficial to access the training data of athletes and monitor some physical activities of patients synchronously.

\subsection{Voice recognition sensing}

Apart from detecting some human physical motions, the pressure sensor is able to recognize different voices of human because of its high sensitivity to applied pressure and the piezoresistive characteristics (Fig. 5d, Additional file 1: Figure S5). A fabricated pressure sensor has been attached to the neck of the volunteer to detect the muscle motions. When the volunteer pronounces
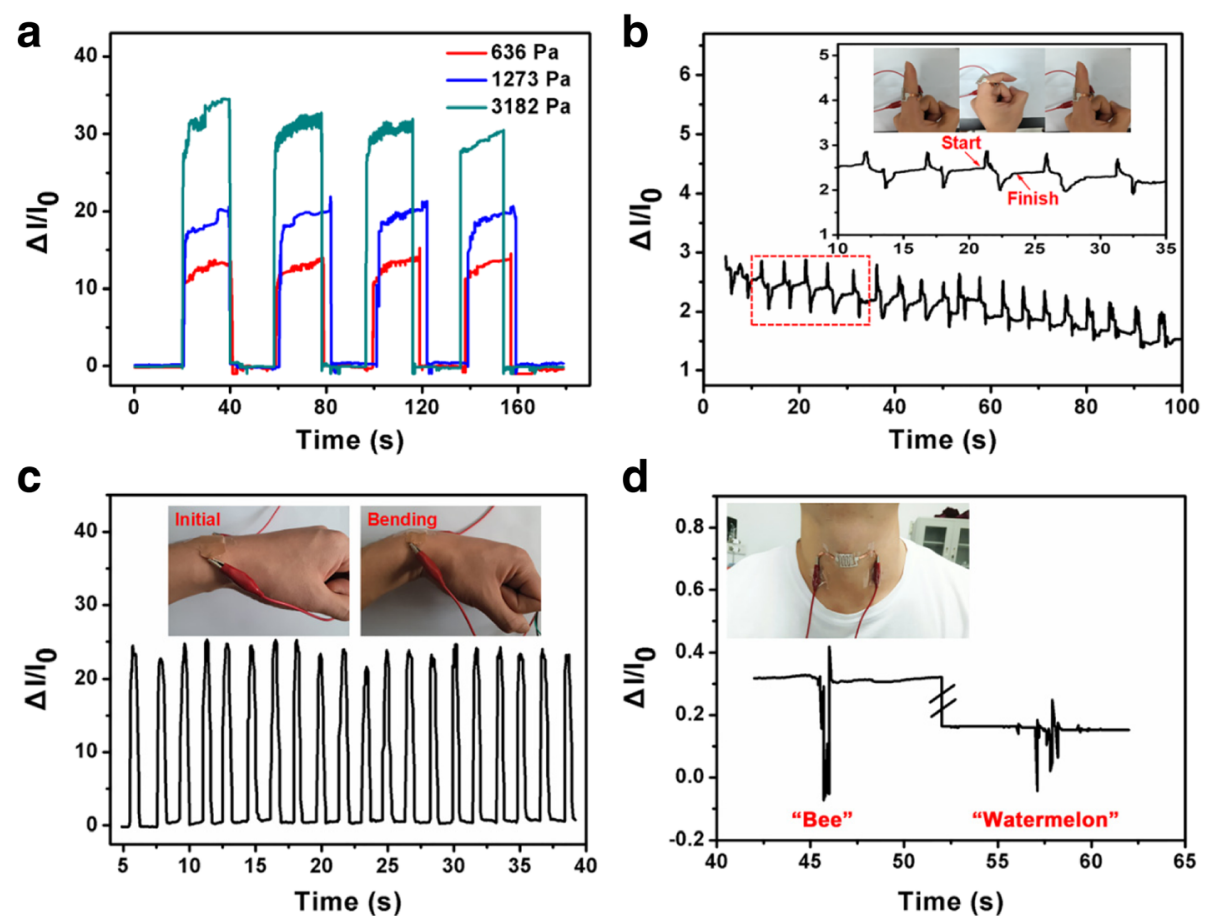

Fig. $\mathbf{5}$ Human motion detection and voice recognition. a Instant current changes of the sensor with different applied pressure. $\mathbf{b}$ Current signals of the sensor that was fixed on an index finger of the volunteer at bending-releasing motions. The top insets in $\mathbf{b}$ show a zoomed-in view of the red-boxed area. c Current signals of the sensor that was fixed on the wrist of the volunteer at bending-releasing motions. The top insets show the photograph of the sensor. $\mathbf{d}$ Recorded current signals versus time when the volunteer pronounced "bee" and "watermelon". The top inset in d shows a photograph of the sensor attached to the neck of the volunteer 
different words, such as "bee", "apple", "tomato" and "watermelon", different current signals of the sensor are collected. Every graph in Additional file 1: Figure S5 represents one word. The current signal patterns increase corresponding to the increasing syllables of the word. When the volunteer repeats the same word every few seconds, the current signals keep consistent, which indicates the stability of the sensor and easy recovery from the deformation caused by the pressure of muscle motions. Also, when the volunteer pronounces different words, the current signal changes because different words give rise to different muscle motions. The striking differences between these current signals indicate the good performance of the pressure sensor to act as a voice recognition device.

\section{Conclusions}

In conclusion, we have demonstrated the use of regenerated collagen films from leather waste as the substrate for flexible pressure sensors. The prepared pressure sensor has a high sensitivity of $13.33 \mathrm{KPa}^{-1}$ in a range of 64-1909 $\mathrm{Pa}$ and $1.27 \mathrm{KPa}^{-1}$ in a range of 2545-6364 Pa. And the sensor exhibits a response time of $349 \mathrm{~ms}$ and relaxation time of $147 \mathrm{~ms}$ under $636 \mathrm{~Pa}$. Moreover, the sensor has good stability and repeatability from the measurment of current changes responding to applied pressure for repeated loading/unloading operation under $3182 \mathrm{~Pa}$. In addition, the sensor can monitor different ranges of human motions including voice recognition, finger and wrist bending-releasing, which demonstrates its potential applications in speech recognition and synchronously monitoring some physical activities of patients. This work provide a new thought for the development and application of bio-waste materials, such as leather waste in pressure sensing technology, biomedical diagnosis, human-machine interaction and so on.

\section{Experimental section}

\subsection{Preparation of the collagen films}

[BMIM] Cl $(3.0 \mathrm{~g})$ was placed into a $50 \mathrm{~mL}$ dried round flask with magnetic stirrer. Pickled skin powders $(180 \mathrm{mg})$ were added in potions of $3 \mathrm{wt} \%$ of [BMIM] $\mathrm{Cl}$ each time and then microcrystalline cellulose $(30 \mathrm{mg})$ were added as a cross-linker, the process of which was controlled by an oil bath at $100{ }^{\circ} \mathrm{C}$ for $5 \mathrm{~h}$. When the solution is like syrup, the mixture solution was well spreaded on a glass sheet and then immersed into deionized water which served as a precipitator. Then the film was washed several times to ensure the ionic liquid washed away completely. Then a regenerated collagen film was obtained and then dried in a vaccum drier to a constant weight.

\subsection{Characterization of the collagen films}

The morphologies of blank collagen films and Ag NWs/ collagen film were characterized by scanning electron microscopy (SEM) (JSM-7800F, Japan) with an accelerating voltage of $3 \mathrm{kV}$. FT-IR spectra were recorded with a FTIR 460 plus (JASCO, Japan). The thermal properties of collagen films were detected using TGA (TG209-F3, Netzsch) with a ramp of $10{ }^{\circ} \mathrm{C} \mathrm{min}{ }^{-1}$ under $\mathrm{N}_{2}$ atmosphere. X-ray diffraction (XRD) patterns were recorded by Advance diffractometer (AXS D8, Bruker) using Nickel-filtered $\mathrm{Cu} \mathrm{K} \alpha$ radiation $(\lambda=1.5406 \AA)$. UV-vis spectra were measured using Shimadzu UV-1750.

\subsection{Fabrication of the flexible pressure sensor}

Interdigital electrodes of silver paints were painted on a flexible collagen film. Ag NWs were dissolved in ethanol with a concentration of $5 \mathrm{mg} \mathrm{mL}^{-1}$ and the solution was dropped on the other collagen film. It was then spin-coated at a rate of $2000 \mathrm{rpm}$ for $30 \mathrm{~s}$ for three times to obtain a mean sheet resistance of $37 \Omega$ sq. $^{-1}$. Then the two films coated with Ag NWs and silver paints were pressed together with edges and adhered by scotch tape.

\subsection{Performances of the flexible pressure sensor}

The current-voltage $(C-V)$ curves were collected using an electrochemical workstation (CHI 660E) between 0 and $0.5 \mathrm{~V}$ at a scan rate of $0.01 \mathrm{~V} \mathrm{~s}^{-1}$. The other current measurements, including instant current-time curves recorded, human motion detection and voice recognition, were characterized by Keithley 4200 semiconductor characterization system. A $1.1 \times 1.4 \mathrm{~cm}^{2}$ slight glass was covered on the pressure sensor to ensure homogeneous application of external pressure when the sensitivity and stability curves of the sensor were collected. And the pressure in experiments was applied by loading standard weights on the sensor and the size of the effective area is $1.1 \times 1.4 \mathrm{~cm}^{2}$. To measure the performance of the sensor while it was bent, the sensor was attached to the joint of an index finger of the volunteer with adhesive tapes. When the volunteer performed finger bending-releasing motions, the current responses corresponding to bending and releasing motions can be recorded. And when the sensor was attached to the wrist of the volunteer to detect some large range of motions, apparent and repeatable current signals can also be recorded during the wrist bending. The voice recognition tests were also conducted. The sensor was attached to the neck of the volunteer to detect the muscle motions. When the volunteer pronounced different words, such as "bee", "apple", "tomato" and "watermelon", current signals were collected. The applied voltage between the interdigital electrodes was $0.5 \mathrm{~V}$, and the above current signals recorded were current-time $(I-t)$ curves in the measurements. 


\section{Additional file}

Additional file 1: Figure S1. (a) Photograph and (b) SEM image of the collagen fibers. Figure S2. Schematic illustration of the fabrication process of the collagen film from collagen fibers. Firstly, pickled skin powders were added in potions of 3 wt $\%$ of [BMIM] Cl each time and then microcrystalline cellulose were added as a cross-linker. Then, the mixed solution was washed by DI water. Finally, a regenerated collagen film was obtained by spreading the solution on glass and dried in a vaccum drier to a constant weight. Figure S3. SEM image of Ag NWs coated on the collagen film. Figure S4. Instant current-time curves of the device at different resistance states responding to an applied pressure between $318 \mathrm{~Pa}$ and $6364 \mathrm{~Pa}$. Figure S5. Recorded current signals versus time when the volunteer pronounced (a) "bee", (b) "apple", (c) "tomato", and (d) "watermelon". The insets show magnified current signals. (DOCX 1830 kb)

\section{Abbreviations}

[BMIM]Cl: 1-butyl-3-methylimidazolium chloride; A: Area; Ag NWs: Silver nanowires; AXS: Advance diffractometer; C-V: Current-voltage; EDA: Electron donor-electron acceptor; FT-IR: Fourier-transform infrared; g: Gravity unit; 10: The initial current; ILs: Ionic liquids; I-t: Current-time; I-V: Current-voltage; m: Mass; P: Pressure; PDMS: Polydimethylsiloxane; PEN: Poly (ethylene naphthalate); PET: Poly (ethylene terephthalate); PI: Poly (imide); S: Sensitivity; SEM: Scanning electron microscope; TGA: Thermo gravimetric analyzer; UV-vis: Ultraviolet-visible; XRD: X-ray diffraction; $\Delta \mathrm{l}$ : The relative change in the current; $\Delta P$ : The change in applied pressure

\section{Acknowledgements}

The authors acknowledge all volunteers who participated in the project.

\section{Authors' contributions}

$J L$ and BZ contributed equally to this work. $J$ and BZ designed experiments, performed, analyzed the results, and drafted the manuscript. RZ, KZ and RX were responsible for preparation of some experiment materials and some characterizations. JW and WZ helped to revise the manuscript. FH, SL and BZ supervised the project, helped design the experiments, and revised the manuscript. All authors read and approved the final manuscript.

\section{Funding}

The project was supported by the National Key R\&D Program of China (Grant No. 2017YFA0207201), National Natural Science Foundation of China (51702155, 21574065, 21604038, 21504043, 21604040), National Science Foundation for Distinguished Young Scholars (21625401), the Jiangsu Provincial Founds for Natural Science Foundation (BK20170975, BK20160975, BK20160981) and the Natural Science Fund for Colleges and Universities in Jiangsu Province (17KJB480007).

\section{Availability of data and materials}

All data generated or analysed during this study are included in this published article and its supplementary information files.

\section{Competing interests}

The authors declare that they have no competing interests.

Received: 10 June 2019 Accepted: 23 July 2019

Published online: 13 August 2019

\section{References}

1. Someya T, Kato $Y$, Sekitani T, Iba S, Noguchi Y, Murase $Y$, Kawaguchi H, Sakurai T. Conformable, flexible, large-area networks of pressure and thermal sensors with organic transistor active matrixes. Proc Natl Acad Sci U S A. 2005;102:12321-5.

2. Wang C, Hwang D, Yu Z, Takei K, Park J, Chen T, Ma B, Javey A. User-interactive electronic skin for instantaneous pressure visualization. Nat Mater. 2013;12:899.

3. Wu W, Wen X, Wang ZL. Taxel-addressable matrix of vertical-nanowire piezotronic transistors for active and adaptive tactile imaging. Science. 2013;340:952.

4. Chen LY, Tee BC, Chortos AL, Schwartz G, Tse V, Lipomi DJ, Wong HS, McConnell MV, Bao Z. Continuous wireless pressure monitoring and mapping with ultra-small passive sensors for health monitoring and critical care. Nat Commun. 2014:5:5028.

5. Wang X, Gu Y, Xiong Z, Cui Z, Zhang T. Silk-molded flexible, ultrasensitive, and highly stable electronic skin for monitoring human physiological signals. Adv Mater. 2014;26:1336.

6. Pang C, Lee GY, Kim Tl, Kim SM, Kim HN, Ahn SH, Suh KY. A flexible and highly sensitive strain-gauge sensor using reversible interlocking of nanofibres. Nat Mater. 2012;11:795-801.

7. Mannsfeld SC, Tee BC, Stoltenberg RM, Chen CV, Barman S, Muir BV, Sokolov AN, Reese C, Bao Z. Highly sensitive flexible pressure sensors with microstructured rubber dielectric layers. Nat Mater. 2010;9:859-64.

8. Someya T, Sekitani T, Iba S, Kato Y, Kawaguchi H, Sakurai T. A large-area, flexible pressure sensor matrix with organic field-effect transistors for artificial skin applications. Proc Natl Acad Sci U S A. 2004;101:9966-70.

9. Zang Y, Zhang F, Di CA, Zhu D. Advances of flexible pressure sensors toward artificial intelligence and health care applications. Mater Horiz. 2015;2:140-56

10. Schwartz G, Tee BC, Mei J, Appleton AL, Kim DH, Wang H, Bao Z. Flexible polymer transistors with high pressure sensitivity for application in electronic skin and health monitoring. Nat Commun. 2013;4:1859.

11. Kaltenbrunner M, Sekitani T, Reeder J, Yokota T, Kuribara K, Tokuhara T, Drack M, Schwodiauer R, Graz I, Gogonea S, Bauer S, Someya T. An ultra-lightweight design for imperceptible plastic electronics. Nature. 2013:499:458-63.

12. Zou B, Chen Y, Liu Y, Xie R, Du Q, Zhang T, Shen Y, Zheng B, Li S, Wu J, Zhang W, Huang W, Huang X, Huo F. Repurposed leather with sensing capabilities for multifunctional electronic skin. Adv Sci. 2018;1801283.

13. Sun H-S, Chiu Y-C, Chen W-C. Renewable polymeric materials for electronic applications. Polym J. 2016;49:61-73.

14. Wagner S, Bauer S. Materials for stretchable electronics. MRS Bull. 2012;37:207-13

15. Kuribara K, Wang H, Uchiyama N, Fukuda K, Yokota T, Zschieschang U, Jaye C, Fischer D, Klauk H, Yamamoto T, Takimiya K, Ikeda M, Kuwabara H, Sekitani T, Loo YL, Someya T. Organic transistors with high thermal stability for medical applications. Nat Commun. 2012;3:723

16. Han $X$, Chen $X$, Tang $X$, Chen $Y L$, Liu JH, Shen QD. Flexible polymer transducers for dynamic recognizing physiological signals. Adv Funct Mater. 2016:26:3640-8.

17. Zhao Z, Yan C, Liu Z, Fu X, Peng LM, Hu Y, Zheng Z. Machine-washable textile triboelectric nanogenerators for effective human respiratory monitoring through loom weaving of metallic yarns. Adv Mater. 2016:28:10267-74.

18. Sekitani T, Zschieschang U, Klauk H, Someya T. Flexible organic transistors and circuits with extreme bending stability. Nat Mater. 2010;9:1015-22.

19. Moreno S, Baniasadi M, Mohammed S, Mejia I, Chen YN, Lopez MAQ, Kumar N, Dimitrijevich S, Jolandan M. Biocompatible collagen films as substrates for flexible implantable electronics. Adv Electron Mater. 2015;1:1500154

20. Hwang SW, Tao H, Kim DH, Cheng H, Song JK, Rill E, Brenckle MA, Panilaitis B, Won SM, Kim YS, Song YM, Yu KJ, Ameen A, Li R, Su Y, Yang M, Kaplan DL, Zakin MR, Slepian MJ, Huang Y, Omenetto FG, Rogers JA. A physically transient form of silicon electronics. Science. 2012:337:1640-4.

21. Kim DH, Kim YS, Amsden J, Panilaitis B, Kaplan DL, Omenetto FG, Zakin MR, Rogers JA. Silicon electronics on silk as a path to bioresorbable, implantable devices. Appl Phys Lett. 2009;95:133701.

22. Zhu B, Wang H, Leow WR, Cai Y, Loh XJ, Han MY, Chen X. Silk fibroin for flexible electronic devices. Adv Mater. 2016;28:4250-65.

23. Siegel AC, Phillips ST, Dickey MD, Lu N, Suo Z, Whitesides GM. Foldable printed circuit boards on paper substrates. Adv Funct Mater. 2010;20:28-35.

24. Nassar JM, Cordero MD, Kutbee AT, Karimi MA, Sevilla GAT, Hussain AM, Shamim A, Hussain MM. Paper skin multisensory platform for simultaneous environmental monitoring. Adv Mater Technol. 2016;1:1600004.

25. Gong S, Schwalb W, Wang Y, Chen Y, Tang Y, Si J, Shirinzadeh B, Cheng W. A wearable and highly sensitive pressure sensor with ultrathin gold nanowires. Nat Commun. 2014:5:3132.

26. Zhang JM, Zhang J. Advanced functional materials based on cellulose. Acta Polym Sin. 2010;12:1376-98.

27. Jin J, Lee D, Im HG, Han YC, Jeong EG, Rolandi M, Choi KC, Bae BS. Chitin nanofiber transparent paper for flexible green electronics. Adv Mater. 2016;28:5169-75.

28. Veeger L. Ecological procedure to solve the tannery waste problems. J Am Leather Chem Assoc. 1993;88:326-9. 
29. Wang X, Huang X, Chen Z, Liao X, Liu C, Shi B. Ferromagnetic hierarchical carbon nanofiber bundles derived from natural collagen fibers: truly lightweight and high-performance microwave absorption materials. J Mater Chem C. 2015:3:10146-53.

30. Wang X, Liao X, Zhang W, Shi B. Bio-inspired fabrication of hierarchical $\mathrm{Ni}$-Fe-P coated skin collagen fibers for high-performance microwave absorption. Phys Chem Chem Phys. 2015;17:2113-20.

31. Wegene JD, Thanikaivelan P. Conducting leathers for smart product applications. Ind Eng Chem Res. 2014;53:18209-15.

32. Thanikaivelan P, Narayanan NT, Pradhan BK, Ajayan PM. Collagen based magnetic nanocomposites for oil removal applications. Sci Rep. 2012;2:230

33. Gautieri A, Vesentini S, Redaelli A, Buehler MJ. Hierarchical structure and nanomechanics of collagen microfibrils from the atomistic scale up. Nano Lett. 2011;11:757-66.

34. Meng Z, Zheng X, Tang K, Liu J, Ma Z, Zhao Q. Dissolution and regeneration of collagen fibers using ionic liquid. Int J Biol Macromol. 2012;51:440-8.

35. Sun $\mathrm{N}$, Rodriguez $H$, Rahman $M$, Rogers $R D$. Where are ionic liquid strategies most suited in the pursuit of chemicals and energy from lignocellulosic biomass? Chem Commun. 2011;47:1405-21.

36. Brogan AP, Hallett JP. Solubilizing and stabilizing proteins in anhydrous ionic liquids through formation of protein-polymer surfactant Nanoconstructs. J Am Chem Soc. 2016:138:4494-501.

37. Vancov T, Alston A-S, Brown T, Mclntosh S. Use of ionic liquids in converting lignocellulosic material to biofuels. Renew Energy. 2012;45:1-6.

38. Sherman VR, Yang W, Meyers MA. The materials science of collagen. J Mech Behav Biomed Mater. 2015;52:22-50.

39. Weingartner $\mathrm{H}$. Understanding ionic liquids at the molecular level: facts, problems, and controversies. Angew Chem Int Ed. 2008;47:654-70.

40. Huddleston JG, Visser AE, Reichert WM, Willauer HD, Broker GA, Rogers RD. Characterization and comparison of hydrophilic and hydrophobic room temperature ionic liquids incorporating the imidazolium cation. Green Chem. 2001;3:156-64.

41. Zhao H, Xia S, Ma P. Use of ionic liquids as 'green' solvents for extractions. J Chem Technol Biotechnol. 2005;80:1089-96.

42. Renugopalakrishnan V, Bhatnagar RS. Hydrogen-bonded water in collagen structure - a Ft-Ir spectroscopic corroboration. Biophys J. 1984;45:A163.

43. Vidal Bde C, Mello ML. Collagen type I amide I band infrared spectroscopy Micron. 2011;42:283-9.

44. He L, Mu C, Shi J, Lin W. Modification of collagen with a natural cross-linker, procyanidin. Int J Biol Macromol. 2011;48:354-9.

45. Zhao X, Long K, Liu Y, Li W, Liu S, Wang L, Ren L. To prepare the collagen-based artificial cornea with improved mechanical and biological property by ultraviolet-a/riboflavin crosslinking. J Appl Polym. 2017;134:45226.

46. Li WC, Long Y, Liu Y, Long K, Liu S, Wang Z, Wang Y, Ren L. Fabrication and characterization of chitosan-collagen crosslinked membranes for corneal tissue engineering. J Biomat Sci-Polym E. 2014;25:1962-197.

\section{Publisher's Note}

Springer Nature remains neutral with regard to jurisdictional claims in published maps and institutional affiliations.

\section{Submit your manuscript to a SpringerOpen ${ }^{\circ}$ journal and benefit from:}

- Convenient online submission

- Rigorous peer review

- Open access: articles freely available online

- High visibility within the field

- Retaining the copyright to your article

Submit your next manuscript at $\boldsymbol{\nabla}$ springeropen.com 